\title{
Electronic Kit Controller to Increase a Motorcycle Engine's Power and Torque
}

\author{
Supriyono $^{1^{*}}$, Iman Mawardi ${ }^{1}$, Abdul Rohman ${ }^{1}$, M Ghozali $^{1}$, FajarSuryawan $^{2}$, Waluyo Adi Siswanto ${ }^{1}$ \\ ${ }^{1}$ Department of Mechanical Engineering, UniversitasMuhammadiyah Surakarta, Indonesia \\ ${ }^{2}$ Department of Informatics, UniversitasMuhammadiyah Surakarta, Indonesia \\ * Corresponding author: supriyono@ums.ac.id
}

\begin{abstract}
The aim of this work is to develop an electronic kit controller for motorcycle engine, to be able to increase power and torque than standard one. The kit developed is based on Arduino Uno microcontroller. The test engine is a 108.2 cc cylinder capacity Honda PGM-FI eSPwith compression ratio of 9.5:1. The testing engine has applied electronic control unit (ECU) to maintain its combustion closed to stoichiometric condition at certain air fuel ratio (AFR) which is considered as the most optimum engine performance. It has an Oxygen sensor of narrow band type on the exhaust manifold. In this work, the kit will decrease the AFR slightly in order to have more power and torque for the testing engine. Dynamometer test is carried out to evaluate power and torque parameters of the test engines. Emission test is also conducted to have AFR and emission level. The results show that the electronic kit controller developed as part of this work increases the test engine's power and torque. The emission levels are still below the permitted level.
\end{abstract}

Key words: ECU, Arduino Uno, Dynotest, Gas analyzer, Engine performance

\section{INTRODUCTION}

The existence of technology of engine management system (EMS) makes performance of the current engine extraordinary. EMS is electronic control with a computer-based (microcontroller) called the engine controlunit (ECU). The EMS technology was initialized by injection technology found by Robert Boschin 1927. This technology originally is used for aircraft then it is expanded to the luxury cars in Germany. Currently this technology is applying on motorcycle as well.

Research on electronic engine control is began in the late 1970s, the goal of which was to improve vehicle fuel efficiency, maximize engine performance and reduce exhaust emissions [1]. Demands on engine performance and also relevant rules on emissions encourage research on engine technology. Since the engine control system directly determines vehicle performance and emission levels, most scholars focus on engine control and have gained much research achievements. There are 6 basic control problems, namely the ratio of fuel air (AFR), electronic throttle control (ETC), idle speed control, ignition timing control, knocking detection and on-board diagnostics.

The air-fuel ratio is a most important factor that influences the performance of a gasoline engine. Dynamic efficiency and engine fuel consumption will decrease with inaccurate AFR controls; meanwhile exhaust emissions will increase. The air-fuel mixture for each cycle must be produced precisely in accordance with the correct ratio to reduce the emission. The amount of fuel injection must be calculated on the basis of the mass flow of air into the cylinder[2].

In gasoline engine with electronic fuel injection (EFI), most AFR control strategies are built on steady state. This method ignores the vacuum fluctuations of the mass of the incoming air, the effect of wetting the chamber walls by the fuel and the effect of delay time under transient conditions. These factors will cause to low control accuracy [3]. But, the control theory development and also sensor technology development, the right AFR control can be done. For example, the research by Yildiz, et al.[4], proposed the average AFR value of combining steady stateandtransient conditions. Rupp et al. [5] conducted experiments regarding AFR control with lambda sensors. They also made simulations of the experiments.

Wang et al.[6], provided an adaptive model of AFR control based on neural network models. This modelcan be used to handle non-linear systems and uncertain parameters.He et al. [7], modeled an engine with an input sensor for AFR. It is based on the dynamics of combustible and exhaust gas. Cavina et al. [8] introduced the design of a closed-loop AFR control system using a spectrum of oxygen sensors. The oxygen sensor detects the oxygen content of the exhaust gas which is then used to adjust the fuel injection according to AFR.

Song et al.[9]controls AFR for gasoline engines to overcome estimations of air flow ratesby developing physics-based AFR using two online correction factors for increased accuracy It uses anextended state predictor observer (ESPO) to estimate total disturbance and predict AFR.Montasser and Samra [10] 
Supriyono et al., International Journal of Emerging Trends in Engineering Research, 8(6), June 2020, 2564- 2567

created asmart mechatronic system developed to controlspark plug ignitionengines. Study by Kumar et al. [11] analyzed the AFR problem by a cycle-based model.

Motorcycle is the most popular transportation mode in Indonesia. Currently, AFR control has already been applied on almost new motorcycle in Indonesia. The ECU installed in motorcycle is fixed to keep AFR at the value closed to stoichiometric conditions. Ideally, the perfect value of AFR is about 15: 1, however the perfect AFR value does not represent the maximum power and torque. It represents the perfect combustion which lowest emission levels. The maximum power is achieved from AFR of 12.6:1. An electronic kit controller is designed for motorcycle to improve power and torque compared to the regular one. However, it maintains the emission under permissible levels. The kit will be fabricated based on an Arduino microcontroller.

Arduino is designed to make it easier for anyone who wants to study electronics and programming to have a variety of interactive things that can interact with us and the environment [12]. Additionally,Barber and Crespo[13]utilized Arduino as low-cost hardware, to have connection in betweenSimulinkand training tools for the control system of undergrad Control Engineering subject at Carlos III University of Madrid.The connection is through the data acquisition card which was very expensive. By replacing it with Arduino, the cost became cheaper. Drost et al. [14]designed and tested a pulsatile flow pump that can be programmed with Arduino. The aim is to build a compact and affordable price system and is relatively easier to program.

The application of Arduino on the automatic control and robotics can be obtained from the work of Candelas, et al. [15]. The use of Arduino in laboratory work at the University of Alicante Spain attracted the interest of students to know about the configuration and programming of hardware. Chen et.al[16] employed Arduino in automation and control. The work is formation of multiple robotic arms for material conveyance inproductionline. Other example of using Arduino on automatic control vehicle's safety can be study from the work by Saxena, [17]. The control isused to prevent collision of the vehicle. Based on the measured distance of a vehicle with a thing in front of it, the safety device of the vehicle will alert the driver in a number of ways. Kiruthikamani, et.al[18] made vehicle's security device on Arduino to locate and turn off stolen vehicle.This device is very reliable, low-priced and welcoming to users which can facilitate straightaway discover a stolen vehicle. As far as the information of the researcher, there is very narrow works on the usage of Arduino for control engine.

\section{METHODOLOGY}

In this study, an engine of Honda PGM-FI eSP is employed as a testing engine. The cylinder capacity of the engine is 108.2 cc. The compression ratio of the engine is 9.5:1. In order to maintain AFR closed to stoichiometric condition $(\mathrm{AFR}=14.72)$ a narrow band type of oxygen sensor is applied [19]. Monitoring of the oxygen content of the exhaust gas is placed on the exhaust manifold. The voltage range of the narrow band style oxygen sensor is about 0 volts to 1 volts, depending on the oxygen concentration in the exhaust gas. The sensor will have lower voltage if the oxygen content is higher and it will have higher voltage if the oxygen content is lower. Based on the sensor voltage, the ECU will control the fuel injection to maintain the constant AFR.

For a narrow band oxygen sensor, the stoichiometric conditions can be achieved if its voltage is in the range of approximately 0.2 volts to 0.7 volts [20]. On the other hand, relationship between power and AFR say that AFR should be decrease from the stoichiometric condition to have more Power and torque of an engine. The maximum power will be achieved for AFR equal to 12.6:1. However, in terms of fuel consumption and emission, it is not the ideal combustion. That is why, in this work, the strategy to have more power and torque of the testing engine is to decrease slightly its AFR, so in terms of fuel consumption and emissions, it will not change too much.

In order to be able to do the job, the electronic kit controller developed in this work, has to ensure that the control system of the testing engine always have a richer air-fuel mixture. The easiest way to do this is to manipulate the voltage of the oxygen sensor output so the input voltage to the main ECU is in the range of about 0.5 volts to 0.8 volts [19]. Based on this idea, an algorithm for the programming of the electronic kit controller can be defined as follows: if the oxygen sensor output voltage is less than 0.5 volts, the kit controller provides a voltage of 0.5 volts to the main ECU, else if the oxygen sensor output voltage is more than 0.8 volts the kit controller supplies a voltage of 0.8 volts to main ECU.

The $\mathrm{C}$ programming language is used to build a source code from the algorithm. The source code is compiled then it is installed to the Arduino Uno microcontroller. Once the installment is completed, the control kit is ready to be verified. The first verification is working test. It is to ensure that the electronic kit controller works properly as the algorithm. The test is conducted according to the wiring diagram as shown in Figure 1. A power supply and a potentiometer are used to simulate the oxygen sensor output voltage. Two voltmeters are utilized. The first voltmeter is to display the simulated voltages produced from power supply and potentiometer as an input for the kit. The second voltmeter is to display the output voltage of the kit which is to be the input for the main ECU. In this works, the output voltage comes from pin number 9 of Arduino. The pin number 9 support pulse width modulation (PWM) signal. It is digital signal that can be treated as analog signal. Besides using voltmeter as measurement media for the voltages, an oscilloscope is also used for more accurate measurement. 
After the first verification is completed and the kit is working properly, the next step is setting up the electronic kit controller to the testing engine. To do so, the illustration as in Figure 4 is followed. The electronic kit control is positioned in between oxygen sensor and main ECU.

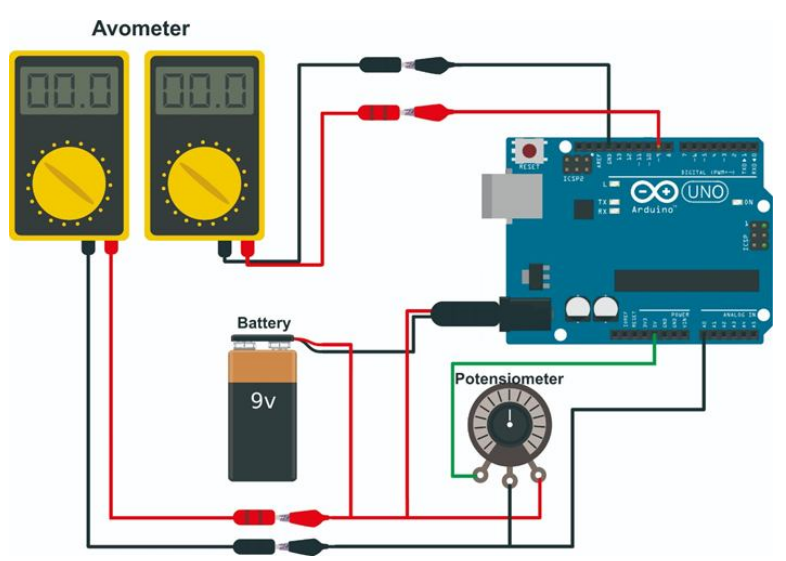

Figure 1: Wiring diagram of the beginning test.

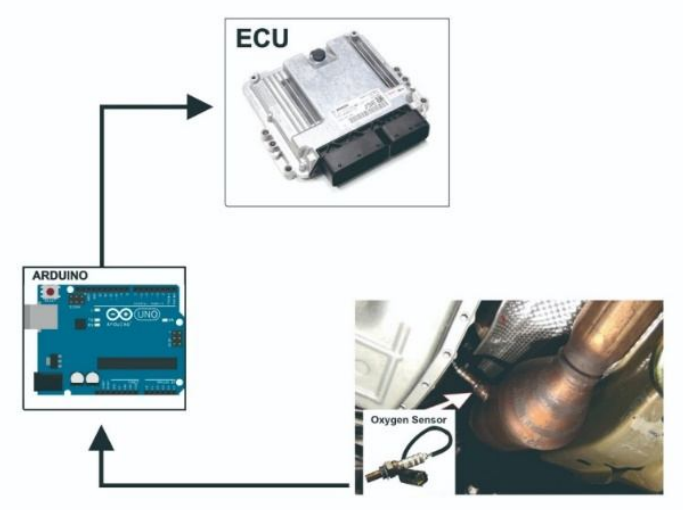

Figure 2: Illustration of installation on the testing engine

Once the setting up is finished, the next step is dynamometer and emission tests. The tests are conducted at every rotation to provide the strength and torque for the test engine. The testing of the dynamometer is done on the SportdynoV3.5. Another check is for pollution. The emission test on the Heshbon automotive emission analyser HG-520 is performed. This test is done to study the level of emissions and to ensure that the emissions are at the level tolerable.On a regular engine and the one with electronic system controller, the dynamometer and emission tests are carried out.

\section{RESULTS AND DISCUSSION}

The dynamometer test results are shown in Figure 3 and Figure 4. Figure 3 shows the power comparison between standard engine and the one with the electronic kit controller. While, Figure 4 is the comparison of the torques of the two test engines. It can be seen that the electronic kit controller is able to increase both power and torque of the test engines.
Maximum power both for the standard and the one with electronic kit controller is achieved at $2698 \mathrm{rpm}$. The powers at this rpm are $62 \mathrm{HP}$ and $66 \mathrm{HP}$ for standard engine and the engine with electronic kit controller respectively. It means the control kit increases the power about 6.5\%. The maximum value torque is achieved at $2113 \mathrm{rpm}$ with the magnitudes of 16.44 Nm and $16.9 \mathrm{Nm}$ for standard and the one with the kit controller respectively. It means the electronic kit controller increases the torque about $2.8 \%$.

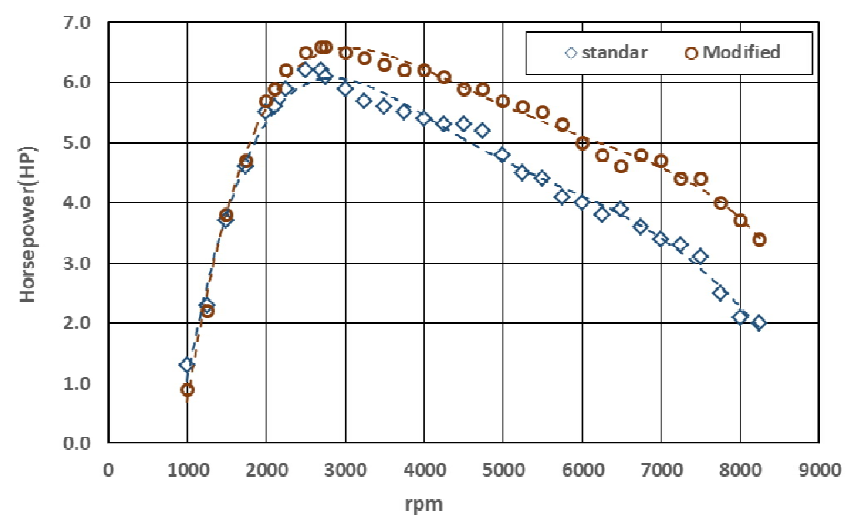

Figure 3: Power test result of dynamometer test

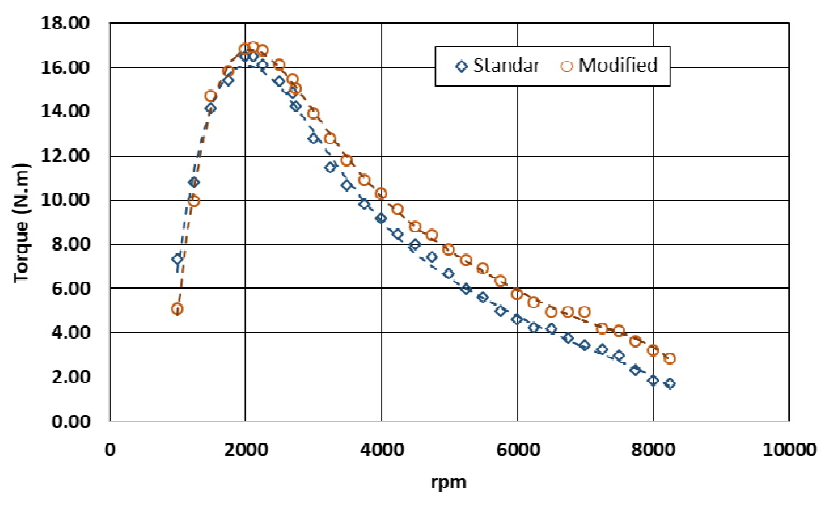

Figure 4: Torque result of dynamometer test

The results of the emission tests are presented in Table 1. It can be seen the electronic kit controller decreases the values of AFR, $\mathrm{CO}$ content, $\mathrm{CO}_{2}$ content, and lambda. It increases $\mathrm{HC}$ content. As it was mentioned in the above paragraph in order to increase power and torque the AFR should be decreased.

Table 1: Emission test results.

\begin{tabular}{cccc}
\hline Test items & Standard & ECU extension & Ideal \\
\hline AFR & $14.2: 1$ & $14: 1$ & $14.7: 1$ \\
CO (\%) & 0.42 & 0.39 & $<3.5$ \\
HC (ppm) & 128 & 193 & $<300$ \\
$\mathbf{C O}_{2}(\%)$ & 8.4 & 6.3 & $12-16$ \\
LAMBDA & 0.970 & 0.957 & 1 \\
\hline
\end{tabular}


Supriyono et al., International Journal of Emerging Trends in Engineering Research, 8(6), June 2020, 2564- 2567

The decrease of AFR is followed by the decrease of lambda and increase of fuel consumption. This has an effect on the increase in $\mathrm{HC}$ content as fuel consumption affects the fluctuation of $\mathrm{HC}$ content. Richer mixture of air and fuel results in higher $\mathrm{HC}$ content due to the slow combustion process, so that the fuel comes out before the fuel burns completely [21]. The test engine, however, shows stronger combustion, as $\mathrm{CO}$ and $\mathrm{CO} 2$ rates decrease. In this case, the increase in power and torque is reported as the fuel pumped into the combustion chamber increases.

For the Arduino and microcontrollerreferences in various applications can be found in [22-24]

\section{CONCLUSION}

The electronic kit controller based on Arduino microcontroller, which is capable of increasing the power and torque of the motorcycle engine, has been successfully obtained. The increases are due to the increase of fuel consumption. It is shown by the decrease values of AFR and lambda. From the emissions point of view, the electronic kit controller changes the emission levels however the values of the emissions are still below the permissible levels.

\section{Acknowledgment}

The authors wish to express their gratitude to the Indonesian Ministry of Technology and Higher Education, under contract No 199.61 / A.3-III / LPPM / V/2019 for this research.

\section{REFERENCES}

1. C. Hong, G. Xun, H. U. Yun-Feng, L. Qi-Fang, G. Bing-Zhao, \& G. Hong-Yan, (2013). Automotive control: the state of the art and perspective. ActaAutomaticaSinica, 39(4), 322-346. https://doi.org/10.1016/S1874-1029(13)60033-6

2. L. Xiao-Liang, W. Sheng-Chang, \&L. Mao-Yue, (2008). Research on air-fuel ratio control and time delay. Highways and Automotive Applications, 2, 11-14.

3. E. G. Gonzalez, J. A. Florez, \&S. Arab, (2008). Development of the management strategies of the ECU for an internal combustion engine: computer simulation. Mechanical Systems and Signal Processing, 22(6), 1356-1373. https://doi.org/10.1016/j.ymssp.2007.11.030

4. Y. Yildiz, A. Annaswamy, D. Yanakiev, \&I. Kolmanovsky, (2008). Adaptive air fuel ratio control for internal combustion engines. In 2008 American Control Conference (pp. 2058-2063). IEEE..

5. D. Rupp, C. H.Onder, \&L. Guzzella, (2007). Iterative adaptive air/fuel ratio control. IFAC Proceedings Volumes, 40(10), 593-599.

6. S. W. Wang, D. L. Yu, J. B. Gomm, G. F. Page, \&S. S. Douglas, (2006). Adaptive neural network model based predictive control for air-fuel ratio of SI engines. Engineering Applications of Artificial Intelligence, 19(2), 189-200.

https://doi.org/10.1016/j.engappai.2005.08.005

7. B. He, T. Shen, J. Kako,\&M. Ouyang,(2008). Input observer-based individual cylinder air-fuel ratio control: modelling, design and validation. IEEE Transactions on Control Systems Technology, 16(5), 1057-1065.

8. N. Cavina, E. Corti, \&D. Moro, (2010). Closed-loop individual cylinder air-fuel ratio control via UEGO signal spectral analysis. Control Engineering Practice, 18(11), 1295-1306.

9. K. Song, T. Hao, \&H. Xie, (2018). Disturbance rejection control of air-fuel ratio with transport-delay in engines. Control Engineering Practice, 79, 36-49. https://doi.org/10.1016/j.conengprac.2018.06.009

10. O. A. Montasser, \&M. E. G. Samra, (2014). Smart PC Based System to Control the Air-Fuel Ratio in SI Engines for Best Performance. International Journal of Current Engineering and Technology, 4(5), 3508-3518.

11. M. Kumar, \&T. Shen, (2017). In-cylinder pressure-based air-fuel ratio control for lean burn operation mode of SI engines. Energy, 120, 106-116.

12. G. W. Recktenwald, \&D. E. Hall, (2011, June). Using Arduino as a platform for programming, design and measurement in a freshman engineering course. In Proceedings of the American Society for Engineering Education Annual Conference \& Exposition.

13. R. Barber, M.Horra, \&J. Crespo, (2013). Control practices using simulink with arduino as low cost hardware. IFAC Proceedings Volumes, 46(17), 250-255.

14. S. Drost, B. J. de Kruif, \&D. Newport, (2018). Arduino control of a pulsatile flow rig. Medical engineering \& physics, 51, 67-71.

15. F. A. Candelas, G. J. García, S. Puente, J. Pomares, C. A.Jara, J. Pérez, \&F. Torres, (2015). Experiences on using Arduino for laboratory experiments of Automatic Control and Robotics. IFAC-PapersOnLine, 48(29), 105-110.

16. C. L. Chen, T. R. Chen, S. H. Chiu, \&P. L.Urban, (2017). Dual robotic arm "production line" mass spectrometry assay guided by multiple Arduino-type microcontrollers. Sensors and Actuators B: Chemical, 239, 608-616.

17. A. Saxena, (2018). Arduino-Based Automatic Safety Vehicle Control. Research \& Reviews: A Journal of Embedded System \& Applications, 6(2), 11-17.

18. G. Kiruthikamani, B. Abinayaa, B. Saranya, P. Devi, \&R. Gayathri, (2017). Smart Vehicle Safety System Using Arduino. International Journal of Trend in Research and Development, 3(6), 804-807.

19. A. W. Bonnick, (2001). Automotive Computer Controlled Sysytem. Oxford: Butterworth-Heinemann.

20. Y. S. Najjar, A. A. W. Almardini, \&A. J. Sawan, (2019). Comparison of performance using wide-band versus narrow-band oxygen sensors in gasoline engines. Case Studies in Thermal Engineering, 16, 100552. https://doi.org/10.1016/j.csite.2019.100552 
Supriyono et al., International Journal of Emerging Trends in Engineering Research, 8(6), June 2020, 2564- 2567

21. N. E. Jayanti, M. Hakam, \&I. Santiasih, (2014). Emisi Gas Carbon Monooksida (Co) Dan Hidrocarbon (Hc) PadaRekayasaJumlah Blade Turbo Ventilator Sepeda Motor "Supra X 125 Tahun 2006". Rotasi, $16(2), 1-5$.

22. FitriaHidayanti, FitriRahmah and SabtoSeptratama (2020) Design of Single-Axis Solar Tracker based on Arduino Uno Microcontroller, International Journal of Emerging Trends in Engineering Research, 8(4), 983-986.

https://doi.org/10.30534/ijeter/2020/07842020

23. Aaron Don M. Africa, Francis Xavier Asuncion, Raymund Miguel Francisco A. Munchua, Janos Lance Tiberio, Joshua Vincent Ligayo and RaineMattheus Manuel (2019) PCB/Microstrip Antenna Design and Simulation, International Journal of Emerging Trends in Engineering Research,7(8), 157-162

https://doi.org/10.30534/ijeter/2019/09782019

24. Arlene G. Estacio, Vilma C. Pagtalunan, Rio S. Pagtalunan, Ira C. Valenzuela, Lean Karlo S. Tolentino and Jennifer C. Dela Cruz (2019) Characterization of High Temperature Calibration Bath through Stability and Uniformity Tests with Data Acquisition using Standard Platinum Resistance Thermometer and Precision Multimeter, International Journal of Emerging Trends in Engineering Research, 7(10, 388-392.

https://doi.org/10.30534/ijeter/2019/047102019 